\title{
Linguistic Relativity Revisited: The Interaction between L1 and L2 in Thinking, Learning, and Production
}

\author{
Hye K. Pae \\ School of Education, University of Cincinnati, Cincinnati, Ohio, USA \\ Email: hye.pae@uc.edu
}

Received October $1^{\text {st }}, 2011$; revised November $5^{\text {th }}, 2011$; accepted December $9^{\text {th }}, 2011$

\begin{abstract}
The linguistic relativity hypothesis (LRH; a.k.a., Whorfian hypothesis) is reconsidered with respect to second language (L2) acquisition. With ebbs and flows over time, the notion of LRH went through dismissal and resurgence in linguistics, psychology, and anthropology. Empirical evidence gleaned from the pseudo-linguistic domains, such as color categorization, time perception, spatial cognition, and number recognition, supports the weak form of LRH. This article briefly reviews the conflicting views, discusses empirical evidence, and expands the premise of LRH to L2 learning. Of interest is the interface of syntax and semantics in English language learners' (ELLs) ergative verb usage in which ELLs tend to overpassivize English ergative verbs (e.g., appear, happen, break). The source of prevalent overpassivization errors is discussed using the LRH framework.
\end{abstract}

Keywords: Linguistic Relativity Hypothesis; Language and Cognition; Second Language Acquisition

\section{Introduction}

The relationship between cognition and language as well as their reciprocal influence have been a long debated topic in psychology and applied linguistics. The fundamental questions related to the nexus of cognition and language involve whether we "think in language" and whether language shapes our thoughts (Casasanto, 2008). These inquiries are related to linguistic relativity in which linguistic differences yield differences in speakers' thoughts. The linguistic relativity principle ${ }^{1}$ (a.k.a., the Whorfian Hypothesis, the Sapir-Whorf Hypothesis) posits that language shapes the speaker's thought and cognition (Gumperz \& Levinson, 1996; Lucy, 1996; Slobin, 2003). According to this hypothesis, different languages demonstrate a wide range of variabilities in the speaker's semantic categories and linguistic representations. As a result, speakers of different languages perceive the world differently and the conceptual system of the world is constrained by the given natural language (Gentner \& GoldinMeadow, 2003).

Although it postulates a relationship between language and cognition, linguistic relativity does not support unidirectionality or causality from cognition to language. In this regard, linguistic relativity does not share commonality with linguistic determinism which asserts that cognitive processes and thoughts have a causal association with the structure of a language. Along this line, Casasanto (2008) claims that linguistic relativity is different from linguistic determinism because linguistic relativity does not strictly determine the speaker's thought.

Using the linguistic relativity hypothesis (LRH) as a theoretical framework, the purpose of this paper is to 1) review the competing views on the linguistic relativity principle or the Whorfian hypothesis, 2) discuss its significant role in perceptual domains, and 3) expand the linguistic relativity principle to the area of second language (L2) or foreign language (FL) ac-

\footnotetext{
${ }^{1}$ According to Tohidian (2009), the label linguistic relativity is more common in these days.
}

quisition. Specifically, the cognitive and perceptual aspects of LRH will first be discussed. Secondly, the interaction between language and cognition will be discussed with empirical evidence. Next, the linguistic intricacy of English ergative verbs related to overpassivization errors ${ }^{2}$ made by English language learners (ELLs) will be explained using the spectrum of LRH. Finally, the implications of LRH in cross-cultural language learning will be discussed.

\section{Competing Views}

The premise of LRH stemmed from the work of a linguist named Sapir (1929; cited in Tohidian, 2009) who had studied English in comparison to Native American languages and concluded that differences in linguistic features across languages yielded differences in the perception, understanding, and interpretation of the world. This notion was followed and substantiated by the work of Benjamin Whorf (1956; cited in Tohidian, 2009), resulting in a theory referred to as the Sapir-Whorf hypothesis or as the Whorfian hypothesis ${ }^{3}$, which reflects the noteworthy influence of Whorf on theory-building. Later, scholars broke down LRH into two versions according to the degree of intensity: strong LRH and weak LRH (Hunt \& Agnoli, 1991; Tohidian, 2009). The strong form of LRH hypothesizes that language dictates and controls thought and perception, while the weak form of LRH posits that language affects thought. Empirical evidence has rejected the strong form of LRH (Hunt \& Agnoli, 1991; Regier \& Kay, 2009), by raising questions about direct translation from one language to another, the presence or absence of a particular form in a language, and the qua-

\footnotetext{
${ }^{2}$ The term "error" is operationalized as any deviations from the prescribed syntax, regardless of the nature of production or judgment (i.e., transitory mistakes or persistent errors).

${ }^{3}$ In this paper, the term LRH and the Whorfian hypothesis are used interchangeably.
} 
lity of evidence used in Whorf's assertion. The weak form of LRH has also been criticized to be a vague and unprovable hypothesis. However, Hunter and Agnoli (1991) have claimed that LRH can be testable, quantifiable, and falsifiable with respect to the influence of the lexical, syntactic, semantic, and pragmatic aspects of language on cognition and thought.

Over the decades, LRH has gone through ebbs and flows in the field. In the 1960s, the idea of linguistic relativity faded out from the research framework, since the prevalent paradigm in linguistics and anthropology stressed the universal nature of human language and cognition (Pinker, 1994). The linguistic universality hypothesis, motivated by Chomsky's Universal Grammar (UG), posits that the universal repertoire of thought and cognition precedes linguistic constraints each language entails. UG overshadowed the trend in linguistics at the time and resulted in a concomitant dismissal of LRH in psychological inquiry. However, UG has limitations in the capacity of explaining cross-linguistic variations, such as low intertranslationability and loan-word use (Hunt \& Agnoli, 1991). When she published her memoire entitled Lost in Translation: A Life in a New Language, Hoffman (1989) had a poignant penetration into the intertwined nature of language and perception of the world, because a thought expressible in one language does not always map into an equivalency in another. For example, the word "serendipity" cannot be translated into a single Korean word, because there is no corresponding counterpart word in Korean. Korean takes several words in a phrase to express the English word "serendipity". Loan words used in many languages may stem from this translation barrier or a lack of transparent equivalency from one language to another. Hunt and Agnoli (1991) note that "language differentially favors some thought processes over others, to the point that a thought that is easily expressed in one language might virtually never be developed by speakers of another language” (p. 378). However, balanced bilinguals seem to maintain their abilities to think differently in different languages according to the circumstantial demand by going back and forth from one language to another (Hunt \& Agnoli, 1991).

In a similar vein, Casasanto (2008) has pointed out that the anti-Whorfian school of thought is at fault in lumping two different questions together. According to him, the conflation of two distinctively different questions "do we think in language?" and "does language shape thought?" created an artifact in the argument structure and the logical flow of which the anti-Whorfian UG group claimed. Pinker (1994) asserts that the foundational categories of reality are not "in" the world but are imposed by one's culture, calling the direct relationship between thought and language a "conventional absurdity" (p. 47). He further calls the Whorfian hypothesis a myth. However, Garnham and Oakhill (1994) argue that using the different number of words for snow (the well-known example) used in Eskimo and English to support or debunk the relationship between language and cognition is questionable, because the difference in the number of words in the two languages is resulted not from the fundamental difference in thought but from the needs of the environmental condition. They note that one group of English speakers (i.e., skiers) uses a number of different words to refer to snow, which is different from that used by typical English speakers. Casasanto (2008) calls for a need of reframing of Whorf's inquiry into the relationship among language, concept, and experience by discrediting Pinker's (1994) assertion against LRH. He argues that "language can shape the way people think even if they do not think in language” (p. 65).
Effects of linguistic relativity have been reemphasized in the 1990s with empirical experiments in the domains of spatial cognition (Levinson, 1996; Li \& Gleitman, 2002), number (Gordon, 2004; Miller, Major, Shu, \& Zang, 2000), color (Gilbert, Regier, Kay, \& Ivry, 2006; Kay \& Kempton, 1984), and time perception (Boroditsky, 2001; January \& Kako, 2007). Current research has focused on exploring paths in which language influences thought and on determining to what extent language affects cognition (Lucy, 2003; Slobin, 2003). This empirical evidence supports the weak form of LRH. Casasanto (2008) endorses a premise that language can shape the way we think, because speakers of different languages develop unique conceptual repertoires through cognitive processes over time. In addition, Regier and Kay (2009) also note that the perception of the world is filtered through the semantic category of the native language (first language; L1).

Language is an important vehicle for thought, in part, because language facilitates the understanding of others' knowledge and beliefs. Gentner and Goldin-Meadow (2003) emphasize the role of language in the understanding of abstract, relational, information and the integration of spatial information into a meaningful unit. Despite a gap between language and thought, structural differences in languages result in a different construal of the world. Gentner and Goldin-Meadow (2003) have compiled theoretically informed debates on the Whorfian hypothesis, encompassing space, number, motion, gender, mind, thematic roles, and ontological discussion on objects and substances. These inquiries on around three categories of language utility: language as lens, language as tool kit, and language as category maker. The premise language as lens posits that the language we speak shapes our perception of the world. The view language as tool kit concerns as to whether the language we speak expands our ability to represent and rationalize symbolic systems and belief systems. The theme language as category maker relates to whether the language we speak affects how we make the category distinctions, such as spatial semantics and relations, nonverbal classifications, and ontological distinctions between objects and substances. Irrespective of the inquiry differences, consensus converges onto the fact that "language is a powerful mediator of cognition when we speak and much of our lives is spent in language-related activities” (Gentner \& Goldin-Meadow, 2003: p. 11).

\section{Empirical Evidence of the Linguistic Relativity Principle}

Although it does not reflect a complete map of consciousness or thought, language is at least a representational map which varies across languages (Clark, 2003), because speakers selectively choose different information, details, and interpretations based on the representations of reality, depending on the language spoken. A pile of research studies indicates that speakers of different languages view and think about the world in relatively different ways. A claim that language shapes the way we think has been supported by a handful of research findings using pseudo-linguistic stimuli. Experimental evidence has rekindled interests in LRH by examining the extent to which language affects nonlinguistic, semantic, cognition in domains such as space, color, number, and time (Boroditsky, 2001; Casasanto, 2005; Gilbert, Regier, Kay, \& Ivry, 2006; Gordon, 2004; Levinson, 1996; January \& Kako, 2007; Kay \& Kempton, 1984; Li \& Gleitman, 2002; Miller, Major, Shu, \& Zang, 2000; Regier \& 
Kay, 2009). Cultural variations can influence the speaker's perception and thought with respect to the lexical, syntactic, semantic, and pragmatic aspects of language (Hunt \& Agnoli, 1991). As a way to control confounding factors related to a particular language, attempts have been made by designing strictly pseudo-linguistic tests to assess the way in which speakers of different L1s perceive and conceptualize abstract conceptual referents, such as time and spatial orientation. As briefly indicated earlier, Casasanto (2008) argues that Pinker's (1994) assertion of anti-Whorfian is logically fallacious and misleading, indicating that his opposition to LRH is on the basis of ill-formed argument structure.

In a color perception study, Drivonikou and colleagues (2007) have utilized a color identification task and a color detection test to examine a hypothesis that linguistically coded color categories (e.g., green, purple, pink, etc.) influence color discrimination. They found that language showed significantly stronger effects of color discrimination on the right visual field than the left visual field. This asymmetry was attributable to the contralateral projection of visual fields onto cerebral hemispheres and the specializd function of the left hemisphere for language (Drivonikou, et al., 2007). In a subsequent study (Regier \& Kay, 2009), similar results were found in that arbitrary color names influenced color perception in the right visual field only and that color naming across languages reflected universal tendency as well as local linguistic convention. Regier and Kay (2009) have concluded that the view of linguistic relativists was half right with respect to color perception and color naming.

Although the mechanism that an individual's cognitive processes influence linguistic features or vice versa has not been fully mapped out, equating thinking with language is a way to disentangle the relationship between language and thought. Experimental evidence that shows differences across different L1 speakers in the lexicalization of time can be attributable to cross-linguistic differences in the way time duration is represented by speakers of different languages (Casasanto, 2008). A claim that thought is mediated by language to some degree seems to be in agreement (Casasanto, 2008), given that speakers of different languages think differently about time and spatial metaphors. This indicates that language reflects and shapes the organizational structure of temporal representations.

The relationship between time and perception has been investigated with respect to spatial orientation as well. For most western-language speakers, time is semantically perceived as a horizontally organized concept (Boroditsky, 2001). However, this spatial orientation with time does not appear to be universal. This was shown through a cross-language study. Boroditsky (2001) has conducted three experiments to investigate whether language affects the way the speaker thinks about time with Mandarin and English speakers. Mandarin speakers tend to think about time on a vertical plane even when they are thinking for English. For example, Mandarin speakers are faster to confirm that March comes earlier than April when they see vertical object priming in a vertical array than horizontal priming. The extent to which Mandarin-English bilinguals think about time vertically is associated with age of initial L2 exposure and acquisition. Boroditsky (2001) concluded that language serves as an influential vehicle in shaping thought about abstract entities and that L1 plays a part in shaping habitual thoughts to some degree. These results suggest that temporal spatial-time cognition is cross-linguistically sensitive, which is evidenced using spatial metaphors (e.g., "Pushing a meeting forward/ba- ck," "Traditions are handed down through generations," "Her birthday is coming up”; Casasanto, 2008). However, January and Kato (2006) challenged Boroditsky's (2001) study results in terms of validity and its implications. They failed to replicate the finding of Boroditsky's (2001) study. It is still unclear as to the source of the conflicting results. As Casasanto (2008) indicates, designing a stimulus material and its validation are a big challenge in research projects. No matter how carefully the instrument is constructed, any experimental design that relies on comparable performance data between two groups may have confounding effects on group differences and methodological flaws are hardly avoidable (Casasanto, 2008). It is possible that a comparative fallacy obscures systematicity in real group difference by underestimating or overestimating interlanguage relationships.

Psychological and cognitive aspects of categorical perception have also received researchers' attention. The categorization of objects seems to be influenced by the linguistic feature. Ameel and colleagues (2005) showed that French and Dutch bilingual speakers, who came from Belgium and shared one cultural background, classified objects (e.g., bottles and dishes) into a categorization of the shared features of the naming pattern. They concluded that the classification of objects was dependent upon the common features the objects share as well as the languagespecific factors. Color discrimination or perception was also found to be language-specific. For instance, Roberson, Hanley, and Pak (2009) have found that color discrimination thresholds between color categories are different in English and Korean speakers who use different color terms and different threshold boundaries.

A difference of self-perception in the use of different languages was also found. Kemmelmeier and Cheng (2004) had bilingual students from Hong Kong fill in independent and interdependent self-construal scales in both English and Chinese. They hypothesized that there was a significant difference in the self-construal between the two-language groups. When they described themselves in English, the bilingual students showed a more independent self-construal, whereas their self-construal was skewed toward a more interdependent scale when they described in Chinese. This study suggests that language can serve as a cognitive cueing system that prompts to define self-perception according to the language used at the moment in the face of specific situational demands. This finding is in a similar line with an episodic description of multiple identities temporally formed when people talk in different languages (Hunt \& Agnoli, 1991), suggesting that different cultures and different languages lead to different speech acts affected by the language spoken.

Lee (1997) explains the Whorfian hypothesis in terms of the role of language in teaching and thinking in order to improve pedagogical practice by reflecting on the language-mind-experience relationship. The author places an emphasis on the notion of "linguistic thinking," "thought insofar as it is linguistic,” or "language in cognition” (p. 432), because cognitive processes are linguistic in nature. Language and thought are inextricably interrelated entities. As language is closely intertwined with conceptual activity, linguistic thinking plays an integral part in communicative activities and meaning making processes (Lee, 1997). Speakers become linguistically conditioned through a consistent and continuous usage of a speech pattern, because persistent language use contributes to the organization of an experiential reality in a certain way (Lee, 1997). However, Casasanto (2008) warns that the fact that language affects thou- 
ght does not mean that people "think in language" or language plays a privileged role via a special channel in shaping thought. He also suggests that an awareness of cross-linguistic cognitive differences demonstrated by diverse L1 speakers can be a step toward an understanding of the boundaries of cultural diversity. In addition, it can be a tool for investigating how the way of thinking plays out in relation to linguistic activity as well as knowledge acquisition and representation (Casasanto, 2008). These inquiries and activities will facilitate the discovery of the locus and structure of our mental representation through investigation into differences of cross-linguistic cognition and the Whorfian hypothesis (Casasanto, 2008).

\section{Linguistic Relativity Hypothesis and Second- and Foreign-Language Acquisition}

The idea of LRH was also investigated in bilingualism. Kousta, Vinson, and Vigliocco (2008) examined the semantic effect of grammatical gender intricacy (present in Italian but absent in English) using an untimed picture naming task by fluent bilinguals and English native speakers. The Italian-English bilinguals produced more gender-preserving errors with the task in Italian than in English. However, the proportion of gender-preserving errors for bilingual speakers did not show a significant difference from those of either English monolinguals or Italian monolinguals. The authors interpreted these results as intra-speaker relativity in semantic representations for Italian-English bilinguals, indicating evidence for linguistic relativity rather than linguistic determinism.

Given the rekindled interest in linguistic relativity, English ergative verb processing by ELLs provides an excellent example as to how languages and thoughts are interlinked. Ergative verbs in English are intransitive verbs that do not take objects but convey passive meanings in sentences. While the transitive verb is relatively straightforward in terms of its function and usage, the intransitive verb bears several functional layers. Intransitive verbs include ergative verbs and unergative verbs. The unergative verb carries the subject's volitional act (i.e., agentive role; e.g., smile, sleep, walk) and is comparatively transparent at the semantic level, while the ergative verb entails the subject's unwilled or nonvolitional action, and the subject plays a theta role (i.e., patienthood). The ergative verb involves another level of layers, containing two subtypes of the ergative verb. The first subtype of ergatives is the verb which has a transitive counterpart (e.g., break, sink, roll), and the other subtype is the verb which does not have a transitive counterpart (e.g., appear, disappear, emerge).

Because verbs have the power to govern how a sentence conveys who did what to whom, it is crucial to assign the verb's role in a sentence according to the verb characteristics (Pinker, 1994). The importance of the distinction between ergative and unergative intransitive verbs lies in the fact that L2 learners of English tend to overpassivize ergative verbs at a significantly greater rate than they do with unergative verbs (Balcom, 1997; Oshita, 2000; Sorace \& Shomura, 2001). Research shows that this type of errors occurs among speakers of different L1 groups (Ju, 2000; Oshita, 2001; Yip, 1995; Zobl, 1989). Especially when ergative verbs are used with inanimate nouns, the ergative active voice becomes a big hurdle in L2 judgment and production for many ELLs. Critical observations have been made on the tendency of overpassivization of which L2 learners of English compose using ergative verbs. For example, L2 English learners tend to produce incorrect passive sentences like " 4 the battery was died yesterday," instead of "the battery died yesterday.” The subject (the battery) is not capable of carrying out the action, but rather undergoes the action expressed by the verb (died). As such, when the subject is affected by the action of the verb, yielding a passive meaning, the complexity is attributable to ergative verbs (Cowan, 2008). Interesting is that the prevalent overgeneralization of the passive voice is found in advanced ELLs' English production. Master (1991) has compiled a language sample showing this phenomenon. Master (1991) notes that Asian students are more susceptible to this error type than any other groups.

The correct forms of present third person singular and past tense were failed to appear in Issic's performance. [Chinese]

Contrastive analysis was not totally rejected; instead it was emerged as a partial explanation of interlanguage. [Thai]

In markedness theory, when L1 is unmarked and L2 is marked, transfer errors are persisted until the late stages of SLA. [Japanese]

Learning style preference and method are significantly interacted when other variables are controlled. [Taiwanese]

His critical period hypothesis was argued that there is no reason to assume that the language faculty atrophies with age. [Taiwanese]

The mathematical basis of the report is shown the following results. [Japanese]

The content in this paper is used the right form and has three parts. [Hmong]

(Master, 1991: p. 19)

This overpassivization tendency observed in ELLs has resulted in a number of research studies in the recent three decades (Balcom, 1997; Ju, 2000; Kondo, 2005, Oshita, 2001; Perlmutter, 1978; Yip, 1995; Zobl, 1989). This propensity has been explained by numerous hypotheses, including the transitivization hypothesis (Perlmutter, 1978; Yip, 1995), the post-verbal NP movement hypothesis (Balcom, 1997), the unaccusative trap hypothesis (Oshita, 2001), the relationship between argument structure and its morphosyntatic instantiation (Kondo, 2005), the locus of causality (Ju, 2000), and the split intransitivity hierarchy (Sorace, 2000). Some researchers view the problematic overpassivization as false mapping relations between lexical semantics and syntax, while others make connection to syntax-bound optionality.

Despite many explanations generated, there is no study that links the tendency to LRH. If persistent errors are found in a specific grammatical point especially in advanced L2 English learners, it can be speculated that a cognitive mechanism plays a critical role in the process of that particular grammatical point beyond significant L2 exposure and input. The following section discusses how the overpassivization tendency can be explained through LRH with respect to subject agentivity and the interface of syntax and semantics.

\section{Korean English Language Learners' Ergative Verb Processing}

A study by Pae, Schanding, and Kwon (2011), which investigated the Korean ELLs' performance on a grammaticality judgment task of English ergative verbs, showed a dominant overpassivization error pattern in Korean ELLs. The research que- 
ries were analyzed with respect to morphological markings (i.e., presence or absence of " $b e+p . p$ "; i.e., active vs. passive), the hierarchy of agentivity (humans, concretes, or abstracts), noun animacy (animate vs. inanimate), word characteristics (singlewords vs. multi-words), the presence or absence of counterparts (paired vs. nonpaired), and the properties of the ergative verb (state vs. motion). If the locus of the overpassivization relates to cognitive complexity beyond L2 grammatical input, word frequency would not affect the performance of Korean ELLs. As expected, found was no significant association between word frequency and the participants' performance on ergative-sentence judgment and between the sentence length and grammatical judgment in terms of accuracy.

\section{Subject Agentivity}

The animacy and agentivity of subject nouns are closely related to syntactic and semantic characteristics of verbs and following nouns as direct objects. Verb transitivity defines the syntactic structure of sentences and the meaning of sentences (Hinkel, 2002). Transitivity hinges on the parameter of nouns and verbs, such as the subject noun capacity for agentivity, the action capacity of verb meaning, the degree of free will or volition that the subject noun entails, and the lexical characteristics of direct objects. These features of nouns define the sentence parameter in terms of transitivity. The degree of volitionality that the subject shows as an agent can assign the object's role as a patient in the syntactic structure of a sentence (Delancey, 1990).

The linguistic features of English may affect ELLs' capability to process and use passive voice judgment and constructions appropriately or inappropriately in English. In Korean, lexical animacy of nouns is closely tied to the feasibility of noun agentivity and verb transitivity. However, English usually does not rely on noun animacy and its semantic constructs, such as agentivity and patienthood, in the formation of a sentence. Let us look at the sentence, "Ben broke the vase." Ben is the agent of the action, and the vase is the recipient of the action. The reverse order in the sentence (i.e., The vase broke Ben) does not yield acceptable syntax, but "the vase broke" is acceptable in English in which the verb broke becomes an intransitive, and it does not reflect the consideration of intentionality. However, the Korean language imposes the expression of a passive meaning on the sentence structure because the vase cannot be an agent due to its inanimate nature (e.g., 병이 깨졌다; change of status $\rightarrow$ The vase was broken).

The degree of accountability for the action establishes the gradient features of noun agentivity or patienthood. The agentitivity of the subject's role is clear in the example of the sentence "I suffered from a cold," where the subject "I" is clearly not a causer of the verb action "suffer" but a recipient of the verb action. Hence, an overpassivization error is likely to be made by Korean ELLs as in "4 I was suffered from a cold." The patienthood trait becomes more salient than agentivity in the sentence "The pen fell from the desk." The subject, the pen, is obviously the receiver of the verb (fall) action; therefore, the passive form " "The pen was fallen from the desk" comes naturally to many Korean ELLs over the active voice. This type of sentence production and acceptability by English learners points to a cognitive organization related to English ergative verbs, transferred from L1 specificity.

${ }^{4}$ An ungrammatical sentence.

\section{Anthropomorphism}

English is liberal in taking subjects in sentences, regardless of the subject characteristics, as seen in the prevalence of the active voice with inanimate agents in English. In line with Master's (1991) notation on Asian students' tendency to overpassivize, Korean students are inclined to think that inanimate subjects with active verbs are unacceptably anthropomorphic. English permits active voice with an inanimate subject when the verb is an inherent aspect or function of that subject. For instance, the intrinsic utility of a thermometer in a sentence " $A$ thermometer measures the temperature" is a measuring instrument (Master, 1991). According to the anthropomorphic principle, however, the subject should have the ownership of the action in the sentence. Hence, animate nouns are to be used as agents of actions in active voice, while inanimate nouns receive actions that verbs express in passive-voice structures. The thermometer itself cannot measure the temperature, because it is not the doer of the measuring action and because the thermometer is an instrument used for temperature measurement (Master, 1991). It should read "a thermometer is used to measure the temperature” as a proper way of Korean expression. It can also be expressed as "We measure the temperature with a thermometer," because the agent who operates the instrument should serve as a subject in the sentence. This is compatible with the notion of the hierarchy of inanimacy as well. For instance, "the car needs gas" is permissible because the car has a higher animacy value than gas on the hierarachy continuum (Hinkel, 2002). As Hinkel (2002) points out, however, a sentence "the article discusses the government" may become confusing or problematic for Korean ELLs because of the violation of the sheer hierarchy. The "article" is lower than "government" on the continuum of the animacy hierarchy. Hence, the passive form (The government is discussed in the article) tends to be produced or judged by Korean ELLs as an acceptable sentence rather than the active sentence (the article discusses the government).

It seems that the mechanism of language processing is organized by L1 linguistic structures and semantic representations. Since the representation of syntax and semantics stored in the speaker's receptive repertoire is multifaceted, the organization and retrieval of syntax may vary according to semantic knowledge stored in long-term memory and the ability to make use of the connections between syntax and semantics.

\section{The Interface of Syntax and Semantics}

The syntactic structure be + p.p lexicalizes the semantic information in the change of the verb status. The ergative verbs that tend to be overpassivized by Korean ELLs have semantic attributes of both "change" and "recipienthood." For example, in the sentence the bottle broke, the verb broke places the meaning of the verb in the change of status and, at the same time, confines the subject to be the recipient of the action of the verb. This goes against the normative way of Korean expression in which the agentive doer executes the action for the change of status.

Since the verb largely defines how a sentence conveys who did what to whom in what way in what context, the main verb typically dictates the sentence structure and meaning. In English, the subject of the sentence is not always the "doer" of the action of the verb as indicated earlier. The subject of the sentence is the "doer" only when the verb defines as such (Pinker, 1994). For example, the verbs in the following sentences assign 
different roles.

1) a. The teacher gave the student a book. [The subject is doing the giving]

b. The student received a book from the teacher. [The subject is being given to or the subject is doing the receiving]

2) a. He shattered the window. [The subject is doing the shattering]

b. The window shattered. [The subject is being shattered]

The first set 1) of the sentences has two different words that specify the roles of the doer and receiver. However, the second set 2) of the sentences has the same lexicon used with animate and inanimate subjects. Although the verb receive conveys the meaning of "being given," the verb in sentence $1 \mathrm{~b}$ can be interpreted as the subject to be doing the action of receiving. The direction of affectedness by the action of the verb is different between the two sentences. In other words, the subject 2a is the doer or causer of the action and the affected object is the window, whereas the subject of the latter $2 \mathrm{~b}$ is the receiver of the action, which is affected by the action of verb as an experiential entity. The Korean verb equivalencies of the verbs used in the first set are consistent in terms of the role of the head wo- rds and the past markers. The equivalencies of the verbs used in the second set have the same head word, but go through a variation that signals the action-receiving meaning or the change of status (e.g.,--졌다). As seen here, the Korean language imposes passive syntactic-semantics on the verb when a nonanimate subject is used in the sentence. Hence, the deep structure of the second set of sentences are as follows:

3) a. He shattered the window.

$\left[\mathrm{S}+\mathrm{V}_{\text {transitive }}+\mathrm{O}\right] \rightarrow$ transitive

subject: doer object: experiential receiver

b. The window shattered.

[S $\left.+\mathrm{V}_{\text {intransitive }}\right] \rightarrow$ ergative

subject: experiential receiver

c. The girl danced.

$\left[\mathrm{S}+\mathrm{V}_{\text {intransitive }}\right] \rightarrow$ unergative subject: doer

As seen above, the verb dance in 3c does not deviate from the notion that the subject is a doer and does not create complexities as the verb shatter does, as seen in 3b. It is speculated that the organization and representation of L1 linguistic features and semantics play a crucial role in the judgment and acceptance of ergative sentences.

Figure 1 displays a comparison of aggregated accuracy and latency performance by the Korean ELLs. The data points represent logarithmic values for the purpose of placing the data on a same continuum. The passive voice was an incorrect ergative expression, whereas the active form was a correct counterpart. The score indicates that the significant number of Korean learners of English accept incorrect passive forms of sentences as correct expressions. This is consistent with the findings of previous research. Interestingly, the passive form took shorter time in an acceptability judgment task than the active counterpart, which means that the participants tended to accept the passive voice without hesitation. This finding suggests that English ergative verbs are processed based on the meaning of patienthood and the change of status, as it is already registered in L1.

To summarize, the findings of Pae, Schanding, and Kwon's (2011) study suggest that the prevalence of overpassivization is language specific, indicating that there may be an interlanguage rule that requires an additional processing for active voice to be used with inanimate subjects. The ELLs' confusion about erga- tivity and the relationship between the instrumental subject and the verb seems to stem from English-specific linguistic properties. This phenomenon has been observed in English production and judgment by ELLs, but the same pattern has not been found when English native speakers learn other languages, such as Chinese, Japanese, and Spanish (Kondo, 2005; Shan \& Yuan, 2008; Sorace \& Shomura, 2001). The lexical and semantic features of sentence constituents in ELLs' L1 seem to have an impact on their grammaticality judgment, which is related to the implication of LRH. Korean ELLs have particular disadvantages when they process or produce ergative-verb sentences, because their L1 does not have syntactically and semantically derived active voices that intrinsically entail passive meanings, as English does.

\section{Cognitive Mechanism beyond L2 Input}

There is consensus on the positive correlation between L2 input and L2 proficiency level. Since L2 acquisition or learning is a slow process of form-function mapping, explicit and implicit instruction as well as real-life experiences with L2 will lead to optimal learning that enables ELLs to perform successful oral and written production (Ellis, Basturken, \& Loewen, 2001). However, errors associated with ergative verbs do not seem to support the pivotal role of L2 input in SLA. Ironically, the overpassivization of ergative verbs are more likely to be found as persistent errors in advanced ELLs than beginners (Oshita, 2001; Masters, 1991). Then, there should be a cognitive factor that is conditioned by L1 in the process of L2 English ergative verbs. Hunt and Agnoli (1991) have explained the Whorfian hypothesis from a cognitive psychological perspective, and they concluded, supporting the weak version of LRH, that language is a window to view the speaker's thought.

Hoffman, Lau, and Johnson (1986) have also found a difference in the use of stereotypes by bilingual English-Chinese speakers. The English-Chinese bilinguals were first asked to see descriptions of people as to whether they were conformed to either English or Chinese stereotypes. Later the bilinguals were asked again whether certain behavioral descriptions which had not been included in the original stimuli were congruent with the characteristic of the target individual. A difference was found according to the language used. When addressed in English, the participants used English stereotypes, but when asked in Chinese, they used Chinese stereotypes. This finding indicates an activation of unconsciously driven cognition to solve the given task as well as the influence of language on different aspects of thought, suggesting different cognitive factors involved according to the coding system used.

Krashen's (1985) Input Hypothesis, one of his five hypothe-

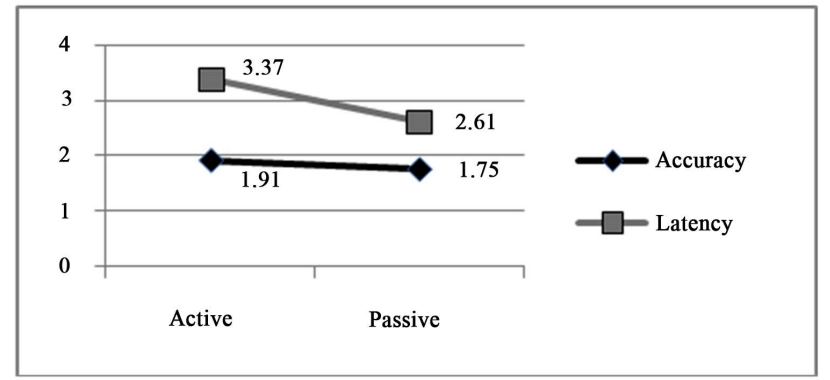

Figure 1.

Korean English learners' accuracy and latency performance on active and passive forms. 
ses in second language acquisition (SLA), has been influential in SLA as a viable theory. According to him, sufficient comprehensible input yields the presence of $i+1$, where $i$ represents previously acquired linguistic competence and knowledge, and comprehensible input leads to grammatical fluency. However, Karshen's hypotheses have been criticized due to a lack of empirical evidence, obscure definitions, and unfalsifiable theory (McLaughlin, 1987). It seems that Korean ELLs' overpassivization of ergative verbs goes beyond Krashen's comprehensible L2 input, as the error pattern is observed in advanced ELLs.

\section{Conclusion}

The proposal that cognition and thought are conditioned by language spoken has been long debated. Speakers who talk differently about the world also think about it differently because language not only reflects the organization of our temporal linguistic and nonlinguistic representations, but also shapes individuals' unique conceptual repertoires (Casasanto, 2008). The weak form of the Whorfian hypothesis has gained social scientists' recurring attention. Despite dismissal, LRH that the semantic organization and structure of a language shape or constrain the ways in which the speaker conceptualizes, understands, and interprets the world has been supported by a multitude of empirical findings. The relationship between language and other cognitive domains, such as spatial cognition, number, color, and time perception, has been well documented (Boroditsky, 2001; Gordon, 2004; Kay \& Kempton, 1984; Levinson, 1996). Pseudo-linguistic experiments and cross-language studies in relation to LRH are essential not only to determine how language affects cognition but also to understand the cognitive consequences of and L1 influences on bilingualism. The cross-linguistic and L1 semantic effects on L2 learning support the canon of LRH. Linguistic features affecting cognitive processes and mechanisms are also reconceptualized with respect to L2 learning.

Irrespective of the passive meaning of the sentence, English ergative verbs refuse to appear in consortium with direct objects and to use them in passive forms because they are essentially intransitive verbs. When English sentences and verbs have a low degree of transparency between syntactic and semantics, the opaqueness of ergative verbs creates confusion for Korean ELLs; as a result, they experience interference from their L1 whose language has consistency between the verb and its semantic properties. Although overgeneralization is a common interlanguage strategy that ELLs utilize when they face difficult or confusing structures of English (Nassaju \& Fotos, 2011), the fact that the overpassivization error is made via sophisticated semantic processing seems to go beyond overgeneralization mistakes. As the reaction time indicates, Korean ELLs tend to take more time and produce more errors, in a sentence acceptability task, with ergative active voice (i.e., correct form) than with ergative passive voice (i.e., incorrect form; Pae, Schanding, \& Kwon, 2011). Ergative passive forms are processed more automatically without delay than ergative active forms. This suggests that conscious control conditioned by L1 appears to be executed in the face of the deep structure of grammatical complexity.

Comprehensible input has been emphasized as a critical concept for ELLs with and without learning difficulties. According to Krashen's (1984) Input Hypothesis, L2 input that is comprehensible leads to an understanding of the essence of syntactic and semantic intricacies of L2. The input hypothesis places va- lues on relevant background, and posits that knowledge and appropriate contextual information are crucial. All evidence centers on the premise that language is an influential tool in shaping thought (Casasanto, 2008; Gentner \& Goldin-Meadow, 2003) and that L1 is a mediator in L2 acquisition or learning (Cowan, 2008; Koust, Vinson, \& Vigliocco, 2008; Master, 1991). This suggests that L2 input alone is not sufficient enough to acquire optimal proficiency of L2.

The implications of ergative verb processing by ELLs have to do with the Whorfian hypothesis. When L1 has a drastically different linguistic structure from that of L2, the linguistic intricacy of L1 may affect L2 acquisition and learning. In addition to this underlying intrinsic mechanism, it becomes a big obstacle for ELLs to internalize the complexity of the English language, when not only must they know the nature of the subject (i.e., agentive or instrumental), but also the features of the verb, such as intransitive, stative, ergative/unaccusative, and unergative, as well as the argument structure and discourse flow (Master, 1991). The pedagogical recommendation is to address the interaction between language and cognition as well as its influence on L2 learning beyond L2 instructional and comprehensible input.

To conclude, if advanced ELLs of different L1 groups persistently make errors in the use of English ergative verbs, it may be an indication that there is a linguistic element that hinders a mastery of L2. This article echoes a quote by Wilhelm von Hamboldt, German educator, linguist, and philosopher: "Language is the formative organ of thought. Intellectual activity, entirely mental, entirely internal, and to some extent passing without trace, becomes through sound, externalized in speech and perceptible to the senses. Thought and language are therefore ... inseparable from each other.”

\section{REFERENCES}

Ameel, E., Storms, G., Malt, B. C., \& Sloman, S. A. (2005). How bilinguals solve the naming problem. Journal of Memory and Language, 53, 60-80. doi:10.1016/j.jml.2005.02.004

Balcom, P. (1997). Why is this happened? Passive morphology and unaccusativity. Second Language Research, 13, 1-9. doi:10.1191/026765897670080531

Boroditsky, L. (2001). Does language shape thought? Mandarin and English speakers' conceptions of time. Cognitive Psychology, 43, 1-22. doi:10.1006/cogp.2001.0748

Casasanto, D. (2008). Who's afraid of the big bad Whorf? Crosslinguistic differences in temporal language and thought. Language learning, 58, 63-79. doi:10.1111/j.1467-9922.2008.00462.x

Chaika, E. (1989). Language the social mirror. New York: Newbury House Publishers.

Clark, E. V. (2003). Languages and representations. In D. Gentner, \& S. Goldin-Meadow (Eds.), Language in mind: Advances in the study of language and thought (pp. 17-24). Cambridge, MA: The MIT Press.

Cowan, R. (2008). The teacher's grammar of English: A course book and reference guide. New York: Cambridge University Press.

Delancey, S. (1990). Ergativity and the cognitive model of event structure in Lhasa Tibetan, Cognitive Linguistics, 1, 289-321. doi:10.1515/cogl.1990.1.3.289

Drivonikou, G. V., Kay, P., Regier, T., Ivry, R. B., Gilbert, A. L., Franklin, A., \& Davies, I. R. L. (2007). Further evidence that Whorfian effects are stronger in the right visual field than the left. PNAS, 104, 1097-1102. doi:10.1073/pnas.0610132104

Ellis, R., Basturkmen, H., \& Loewen, S. (2001). Learner uptake in communicative ESL lessons. Language learning, 51, 281-318. doi:10.1111/1467-9922.00156

Garnham, A., \& Oakhill, J. (1994). Thinking and reasoning. Oxford: Blackwell. 
Gentner, D., \& Goldin-Meadow, S. (2003). Whither Whorf. In D. Gentner, \& S. Goldin-Meadow (Eds.), Language in mind: Advances in the study of language and thought (pp. 3-14). Cambridge, MA: The MIT Press.

Gilbert, A. L., Regier, T., Kay, P., \& Ivry, R. B. (2006). Whorf hypothesis is supported in the right visual field but not the left. Proceedings of the National Academy of Sciences of the USA, 103, 489494. doi:10.1073/pnas.0509868103

Gumperz, J. J., \& Levinson, S. C. (Eds.) (1996). Rethinking linguistic relativity. New York: Cambridge University Press.

Hinkel, E. (2002). Why English passive is difficult to teach (and learn). In E. Hinkel, \& S. Fotos, (Eds.), New perspectives on grammar teaching in second language classrooms (pp. 233-259). New York; Lawrence Erlbaum Associates

Hoffman, E. (1989). Lost in translation: A life in a new language. New York: Dutton.

Hoffman, C., Lau, I., \& Johnson, D. R. (1986). The linguistic relativity of person cognition. Journal of Personality and Social Psychology, 51, 1097-1105. doi:10.1037/0022-3514.51.6.1097

Hunt, E., \& Agnoli, F. (1991). The Whorfian hypothesis: A cognitive psychology perspective. Psychological Review, 98, 377-389. doi:10.1037/0033-295X.98.3.377

January, D., \& Kako, E. (2006). Re-evaluating evidence for linguistic relativity: Reply to Boroditsky (2001). Cognition, 104, 417-426. doi:10.1016/j.cognition.2006.07.008

$\mathrm{Ju}, \mathrm{M}$. K. (2000). Overpassivization errors by second language learners: The effect of conceptualizable agents in discourse. Sea Service Leadership Association, 22, 85-111.

Kay, P., \& Kempton, W. (1984). What is the Sapir-Whorf hypothesis? American Anthropologist, 86, 65-79. doi:10.1525/aa.1984.86.1.02a00050

Kemmelmeier, M., Cheng, B. (2004). Language and self-construal priming: A replication and extension in a Hong Kong sample. Journal of Cross-Cultural Psychology, 35, 705-712. doi:10.1177/0022022104270112

Kondo, T. (2005). Overpassivization in second language acquisition. International Review of Applied Linguistics, 43, 129-161. doi:10.1515/iral.2005.43.2.129

Kousta, S-T., Vinson, D. P., \& Vigliocco, G. (2008). Investigating linguistic relativity through bilingualism: The case of grammatical gender. Journal of Experimental Psychology, 34, 843-858. doi:10.1037/0278-7393.34.4.843

Krashen, S.D. (1985). The input hypothesis: Issues and implications, New York: Longman.

Lee, P. (1997). Language in thinking and learning: Pedagogy and the New Whorfian framework. Harvard Educational Review, 67, 430471.

Levinson, S. (1996). Frames of reference and Molyneux's question: Crosslinguistic evidence. In P. Bloom, \& M. Peterson (Eds.), Language and Space (pp. 109-169). Cambridge, MA: MIT Press.

Li, P., \& Gleitman, L. (2002). Turning the tables: Spatial language and spatial cognition. Cognition, 83, 265-294. doi:10.1016/S0010-0277(02)00009-4

Lucy, J. A. (1992). Grammatical categories and cognition: a case study of the linguistic relativity hypothesis. New York: Cambridge University Press.

Master, P. (1991). Active verbs with inanimate subjects in scientific prose. English for Specific Purpose, 10, 15-33. doi:10.1016/0889-4906(91)90013-M

McLaughlin, B. (1987). Theories of second-language learning. London: Edward Arnold.

Nassaji, H., \& Fotos, S. (2011). Teaching grammar in second language classrooms: Integrating form-focused instruction in communicative context. New York: Routeledge.

Oshita, H. (2001). The unaccusative trap in second language acquisition. Studies in Second Language Acquisition, 23, 279-304. doi:10.1017/S0272263101002078

Park, K-S., \& Lakshmanan, U. (2007). The unaccusative-unergative distinction in resultatives: Evidence from Korean L2 learners of English. Proceedings of the 2nd Conference on Generative Approaches to Language Acquisition North America (GALANA). 328-338. www.lingref.com, document \#1573.

Pae, H. K., Schanding, B., \& Kwon, Y.-J. (2011). Overpassivization of ergatives by adult English language learners. Paper presented at the American Association for Applied Linguistics, Chicago, Illinois.

Perlmutter, D. M. (1978). Impersonal passives and the unaccusative hypothesis. Proceedings of the Berkeley Linguistics Society, 4, 157 189.

Pinker, S. (1994). The language instinct. New York, NY: William Morrow and Company.

Regier, T., \& Kay, P. (2009). Language, thought, and color: Whorf was half right. Trends in Cognitive Sciences, 13, 439-446. doi:10.1016/j.tics.2009.07.001

Roberson, D., Hanley, J. R., \& Pak, H. (2009). Thresholds for color discrimination in English and Korean speakers. Cognition, 112, 482-487. doi:10.1016/j.cognition.2009.06.008

Shan, C.-K., \& Yuan, B. (2008). "What is happened” in L2 English does not happen in L2 Chinese, ERUOSLA Yearbook, 8, 164-190. doi:10.1075/eurosla.8.10sha

Sorace, A., \& Shomura, Y. (2001). Lexical constraints on the acquisition of split intransitivity: Evidence from L2 Japanese. Studies in Second Language Acquisition, 23, 247-278. doi:10.1017/S0272263101002066

Sorace, A. (2000). Gradients in auxiliary selection with intransitive verbs. Language, 76, 859-890. doi:10.2307/417202

Tohidian, I. (2009). Examining linguistic relativity hypothesis as one of the main views on the relationship between language and thought. Journal of Psycholinguistic Research, 38, 65-74. doi:10.1007/s10936-008-9083-1

Yip, V. (1990). Interlanguage ergative constructions and learnability. CUHK Papers in Linguistics (pp.45-68). Hong Kong: Chinese University.

Yip, V. (1995). Interlanguage and learnability: From Chinese to English. Amsterdam: John Benjamins.

Zobl, H. (1989). Canonical typological structures and ergativity in English L2 acquisition. In S. M. Gass, \& Schacter (Eds.), Linguistic perspectives on second language acquisition (pp. 203-221). New York: Cambridge University Press. 